\title{
Assessment of Least Tern and Piping Plover Habitats on the Missouri River Using Remote Sensing
}

Emergent sandbars in the Missouri River are critical breeding habitat for the endangered interior population of least terns (Sterna antillarum) and the threatened Northern Great Plains population of piping plover (Charadrius melodus). A fundamental challenge in riverine habitat evaluation is dealing with the spatial and temporal variability resulting from variation in river discharge. Small changes in discharge can result in large changes in the area of available habitat on low-relief emergent sandbars.

Remotely sensed imagery with high spatial resolution can be used to inventory and map the amount, composition, and juxtaposition of land-cover categories on emergent sandbars at a single instant in time. Interpretation of habitat estimates and trends would be simplified by acquisition of remotely sensed imagery at a similar river discharge at each observation period. However, it is extremely challenging to achieve this image acquisition goal in practice. Alternatively, flow-related variability in habitat estimates can be modeled using imagery acquired at multiple times at a range of discharges, and correlating habitat areas with discharge. Quantification of emergent sandbar area and habitats on multiple dates provides a better characterization of least tern and piping plover habitat relative to estimates from a single date.

Hydraulic models are an alternative method to estimate the area of emergent sandbars as a function of discharge. Bathymetric and topographic survey data are a primary data component of hydraulic models and are difficult and costly to obtain compared to optical remotely sensed imagery. Furthermore, small errors in model predictions of water surface elevation can lead to large errors in estimates of the area of low-relief emergent sandbars, so the utility of these models needs to be evaluated in context of costs, uncertainties, and information content.

Synergistic use of optical remotely sensed imagery and elevation models is a promising approach to riverine habitat evaluation. Optical remotely sensed imagery can be used to inventory habitat characteristics, for example, plant communities and successional stages, which are not obtainable from hydraulic models, and can be used to evaluate predictions of sandbar inundation.

\section{Research Goal and Strategy}

The primary goal of this study is to develop a costeffective method to inventory, map, estimate, monitor, and evaluate least tern and piping plover habitats for four segments of the Missouri River using remotely sensed imagery (fig. 1).

The inventory and mapping objective is to develop a database of the spectral and spatial properties of habitat categories from analysis of a collection of multitemporal remotely sensed images and methods to identify and map habitats. The estimation objective uses probability-based accuracy assessment of the habitat maps to calculate unbiased estimates of the area of habitat categories with standard errors by accounting for omission and commission errors in the maps.

The monitoring objective uses analysis of the habitat maps from different dates to quantify accretion and erosion of sandbars, vegetation succession, bank erosion, and other temporal dynamics in the riverine system. The evaluation objective uses generalized linear models to relate nest density and nest success to habitat metrics derived from the remotely sensed imagery. Replication provided by multisegment (Gavins Point, Fort Randall, Garrison, and Fort Peck segments of the Missouri River) and multiyear analyses will allow assessment of 


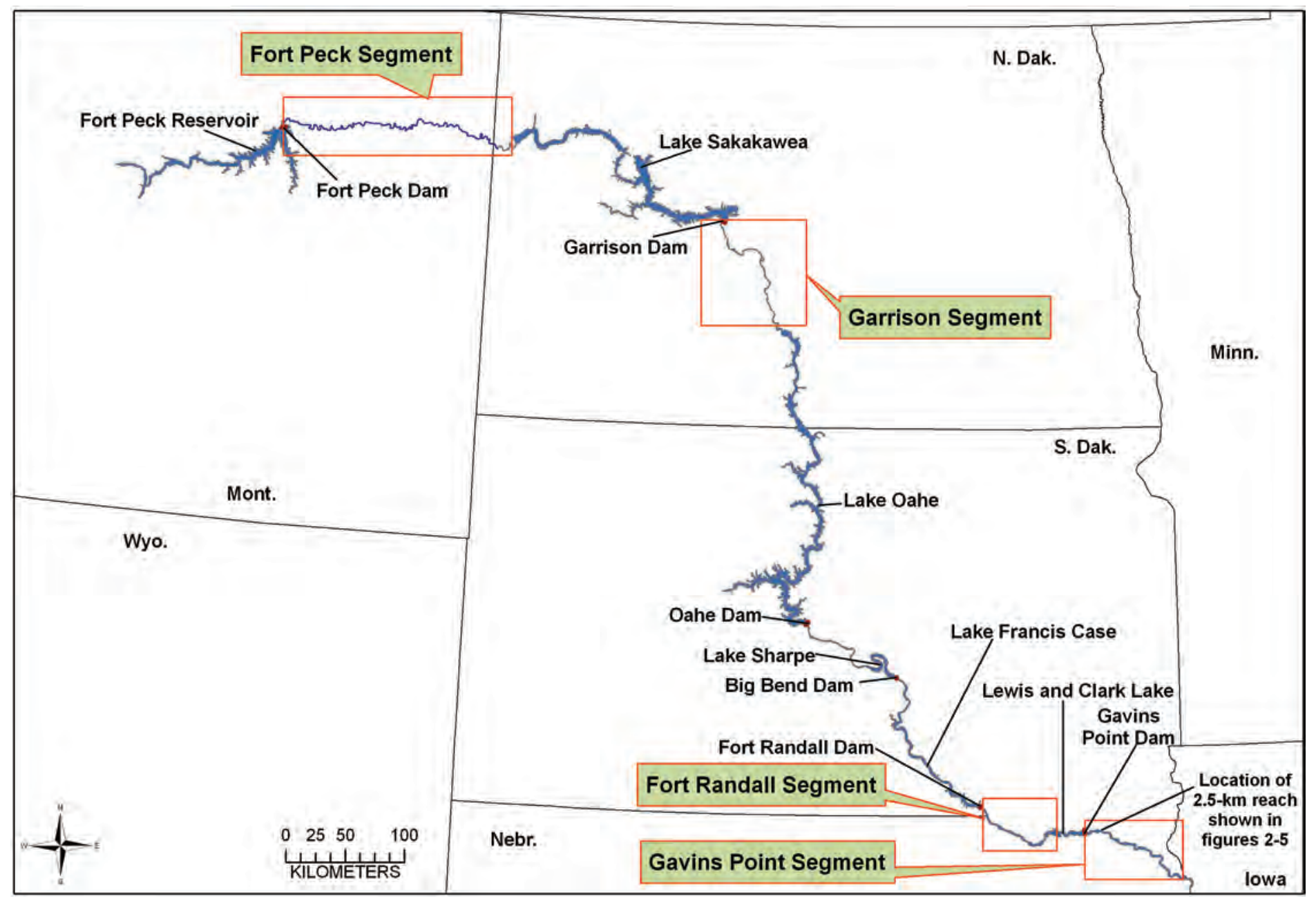

Figure 1. Missouri River and location of four river segments identified in the U.S. Fish and Wildlife Service 2003 amendment to the 2000 Biological Opinion on operation of the Missouri River (http://www.nwd-mr.usace.army.mil/mmanual/FinalB02003.pdf).

the confidence and generality of the predictive value of the habitat variables for describing habitat selection by the birds.

A two-pronged approach provides a cost-effective, relatively simple method to meet the U.S. Army Corps of Engineers short-term habitat mapping and monitoring needs for all four river segments while simultaneously evaluating more complex techniques on the Gavins Point segment for possible future monitoring efforts. Pansharpened multispectral QuickBird imagery (http://www. digitalglobe.com) is being acquired for all four river segments in 2006-08 (fig. 2). Two image acquisitions are attempted for each year: one during the nesting period and the other during the brood rearing period. Imagery is analyzed using hierarchal object-based image segmentation and classification procedures in Definens Developer software (http://www.definiens.com).

For the Gavins Point segment, QuickBird imagery was also acquired in 2005 during June-July $\left(594.7 \mathrm{~m}^{3} / \mathrm{s}\right.$ discharge from Gavins Point Dam), September $\left(707.9 \mathrm{~m}^{3} / \mathrm{s}\right)$, and October $\left(254.6 \mathrm{~m}^{3} / \mathrm{s}\right)$, and LIDAR data were collected in November $2005\left(311.5 \mathrm{~m}^{3} / \mathrm{s}\right)$.
Approaches for predicting sandbar inundation vary in data requirements and assumptions. The Missouri River downstream from Gavins Point Dam is regulated to produce steady to gradually varying flow for long time intervals during typical years. Under these conditions, water-surface elevations can be approximated as sloping planes along the river, and water-surface elevations for discharges of interest can be interpolated between river gaging stations. By subtracting the planar water surface from the bare earth elevation model derived from the LIDAR data, sandbar inundation predictions can be made for areas which were above the water-surface at the time of the LIDAR acquisition (fig. 3). Model predictions of sandbar inundation at discharges corresponding to the time of QuickBird acquisitions can be evaluated by comparison with habitat maps produced from analysis of the QuickBird images (figs. 4 and 5). This approach is simple, avoids the need for extensive bathymetry data, and avoids the expense of compiling, calibrating, and validating hydraulic models. A hydraulic model and bathymetry data would be appropriate if the objective was to simulate a flood wave, to model inundation at discharges for which 


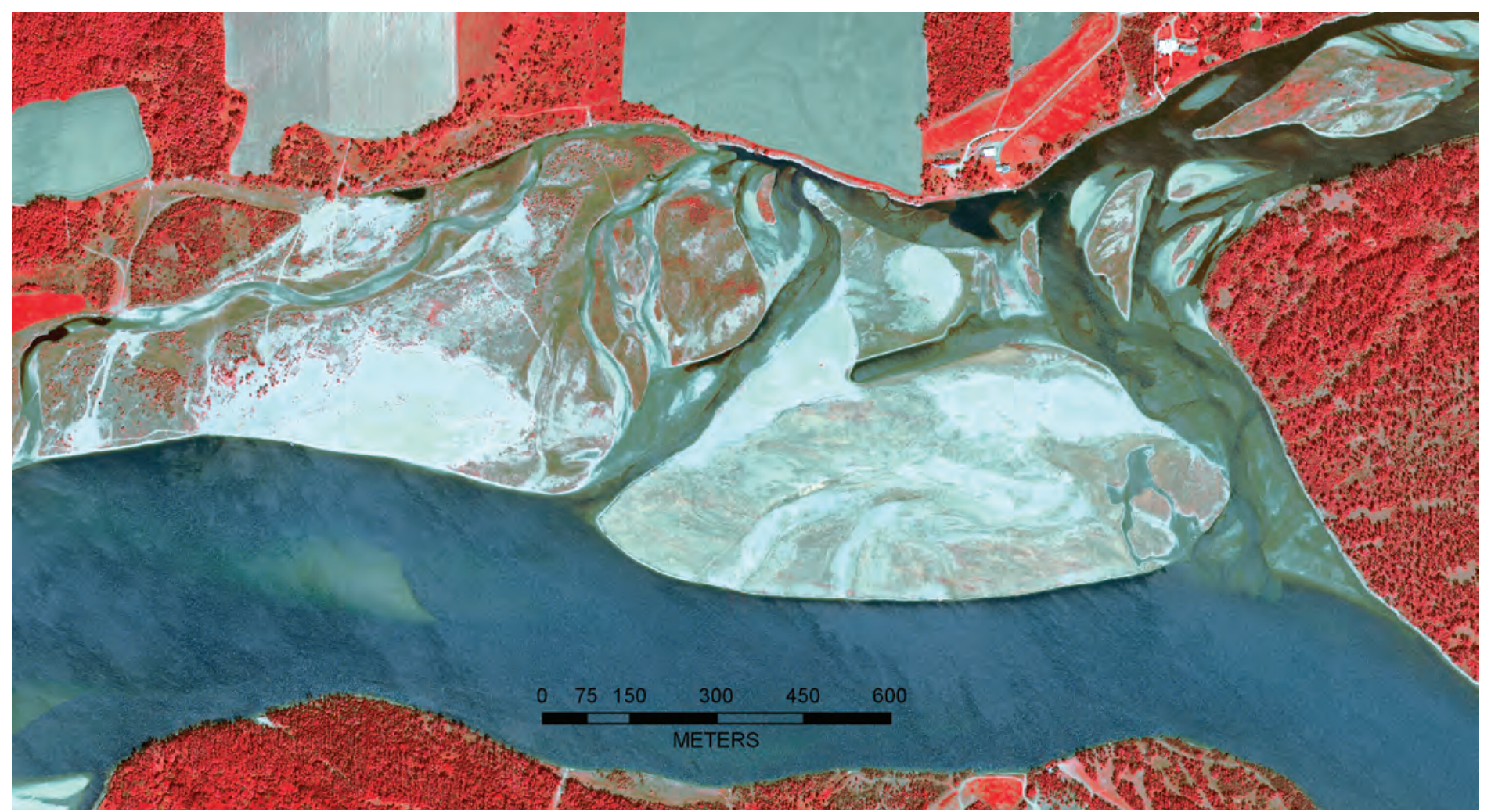

Figure 2. QuickBird color infrared composite for a 2.5-km reach on the Gavins Point segment. Image was acquired May 12, 2006, when discharge from Gavins Point Dam was $455.9 \mathrm{~m}^{3} / \mathrm{s}$.

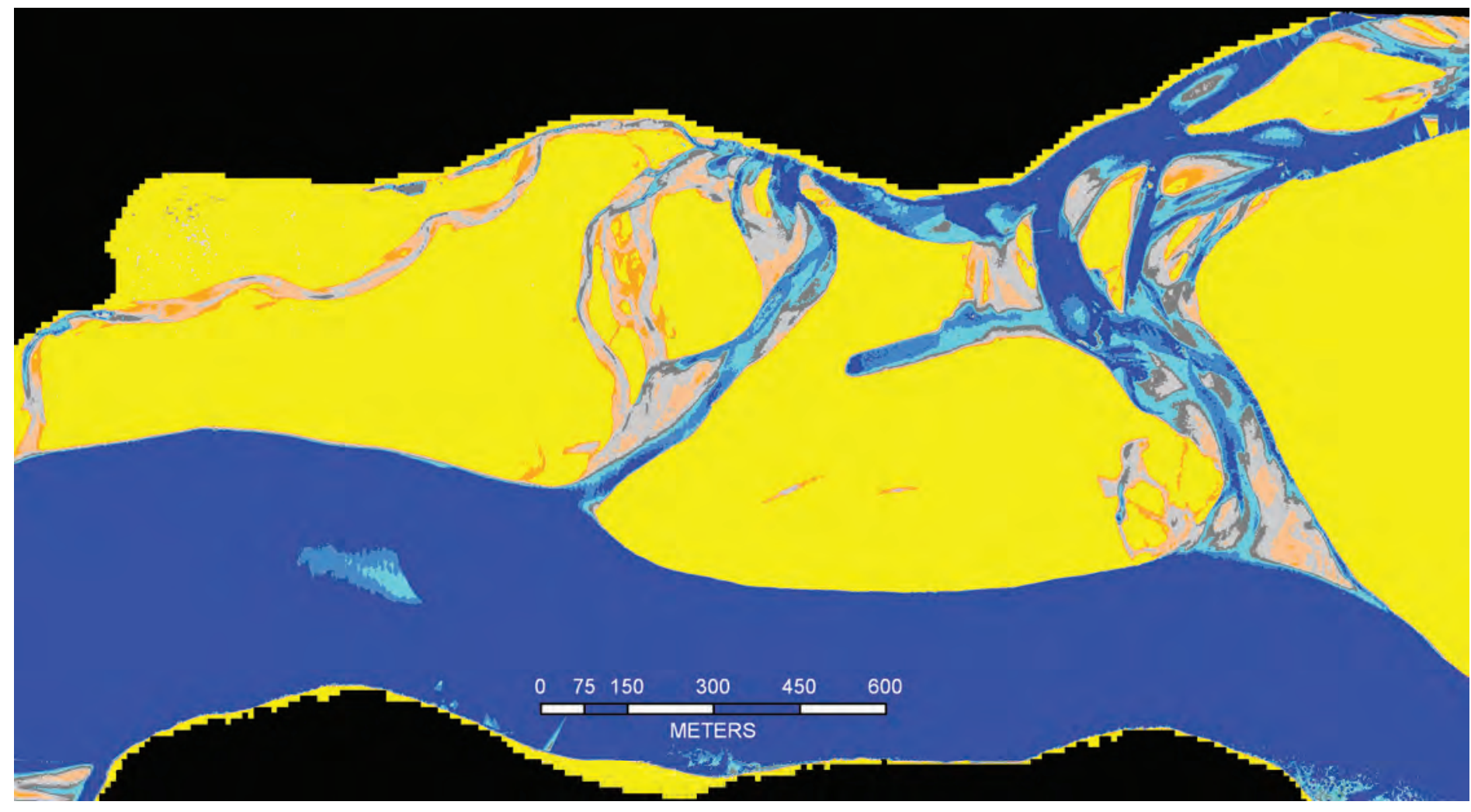

EXPLANATION
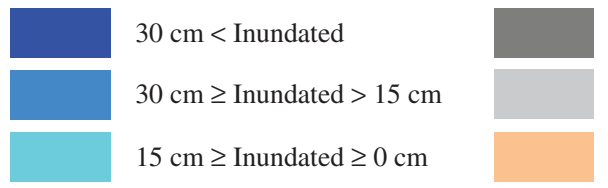

$0 \mathrm{~cm}<$ Exposed $<15 \mathrm{~cm}$

$15 \mathrm{~cm} \leq$ Exposed $<30 \mathrm{~cm}$

$45 \mathrm{~cm} \leq$ Exposed $<60 \mathrm{~cm}$

Exposed $\geq 60 \mathrm{~cm}$

Figure 3. Predicted sandbar inundation corresponding with May 12, 2006, QuickBird acquisition. Colors represent depths of water or heights of exposed surfaces in relation to water surface elevations. 


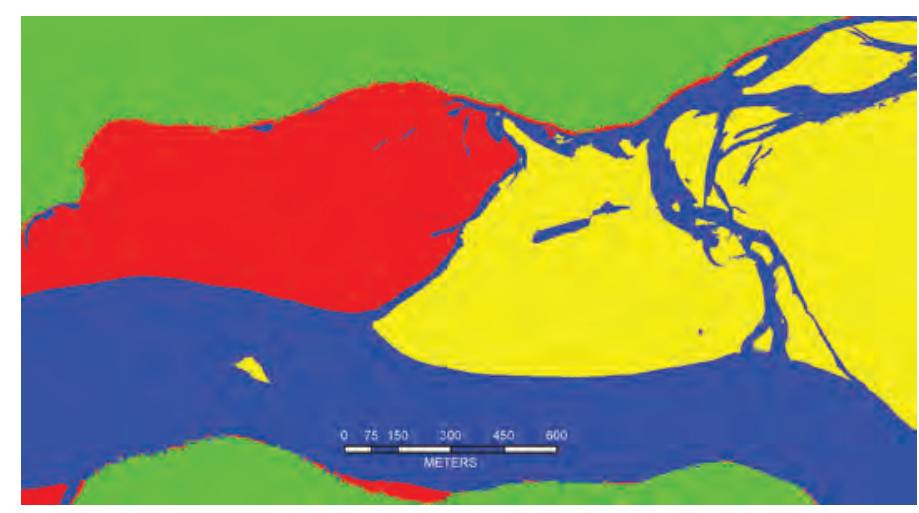

EXPLANATION

Island
$\begin{aligned} & \text { Sandbars attached (sandbars not surrounded by water } \\ & \text { at time of imaging) and flood-plain shoreline }\end{aligned}$
Flood plain
Water

Figure 4. Upper level of two-level hierarchal habitat classification scheme for May 12, 2006.

stage measurements were not available, or to calculate a flow velocity. It may also be necessary to use hydraulic models if water-surface irregularities would produce significant longitudinal errors in predictions of inundated areas.

A preliminary evaluation of the sandbar inundation modeling for the Gavins Point segment corresponding to June 2005 and July 2006 QuickBird imagery has been completed. The agreement between measured (QuickBird imagery) and predicted sandbar inundation was good. Low-elevation portions of sandbars with a wet substrate account for the majority of the commission errors in the inundation predictions (analysis of QuickBird imagery reveals locations are above the water surface but the model predicts inundation). Omission errors for inundation predictions (analysis of QuickBird imagery reveals water at the locations but the model predicts the sandbars are not inundated) are the result of an estimated water surface slightly less than the bare earth elevation. Temporal changes in the distribution of sand between dates of QuickBird imagery and LIDAR undoubtedly account for some of the prediction error, as does non-planar water

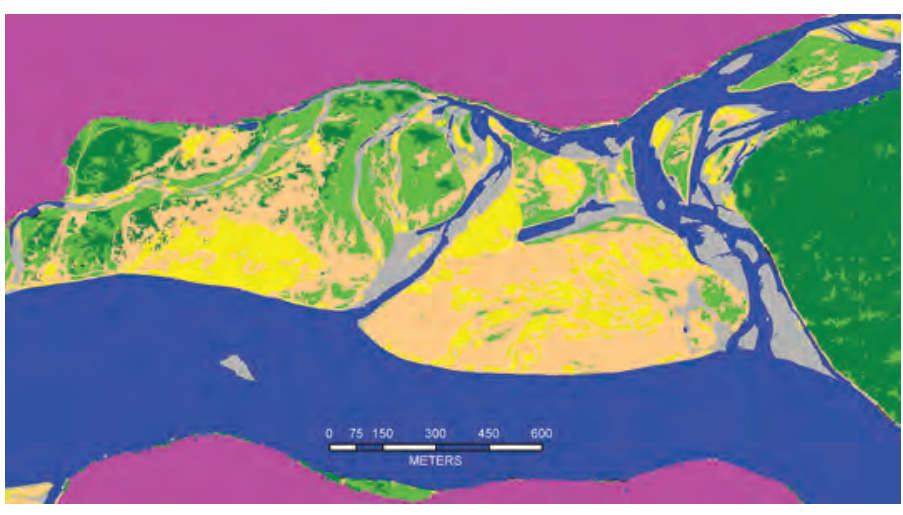

\section{EXPLANATION}

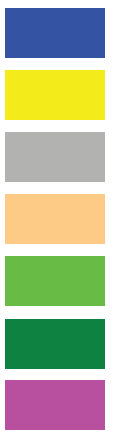

Water

Dry sand

Wet substrate

Herb and shrub vegetation, sparse

Herb and shrub vegetation, continuous

Woodland

Flood plain

Figure 5. Lower level of two-level hierarchal habitat classification scheme for May 12, 2006.

surface elevations. The strength of the agreement between model predictions with habitat maps from 2007 and 2008 QuickBird imagery will provide a measure of the useful lifetime of the bare earth elevation model derived from the November 2005 LIDAR data in this dynamic river environment.

Any use of trade, product, or firm names is for descriptive purposes only and does not imply endorsement by the U.S. Government.

\section{For information contact:}

Larry Strong, Wildlife Biologist

U.S. Geological Survey

Northern Prairie Wildlife Research Center

871137 th Street SE

Jamestown, ND 58401

701-253-5524

lstrong@usgs.gov 